\begin{tabular}{|c|c|}
\hline Title & $\begin{array}{l}\text { Effect of Laves Phase on High-Temperature Deformation and Microstructure Evolution in an 18Cr-2Mo-0.5Nb Ferritic } \\
\text { Stainless Steel }\end{array}$ \\
\hline Author(s) & Ikeda, Ken-ichi; Y amoah, Nana Kwame Gyan; Reynolds, William T., Jr.; Hamada, Jun-Ichi; Muray ama, Mitsuhiro \\
\hline Citation & $\begin{array}{l}\text { Metallurgical and material s transactions A : physical metal lurgy and materials science, 46A (8), 3460-3469 } \\
\text { https://doi.org/10.1007/s11661-015-2936-y }\end{array}$ \\
\hline Issue Date & 2015-08 \\
\hline Doc URL & http:/hdl.handle.net/2115/62575 \\
\hline Rights & The final publication is available at Springer via http://dx.doi.org/10.1007/s11661-015-2936-y \\
\hline Type & article (author version) \\
\hline File Information & Ikeda MMT(46A).pdf \\
\hline
\end{tabular}

Instructions for use 


\title{
Effect of Laves phase on high-temperature deformation and microstructure evolution in a 18Cr-2Mo-0.5Nb ferritic stainless steel
}

\author{
Ken-ichi Ikeda ${ }^{1}$, Nana Kwame Gyan Yamoah², William T. Reynolds Jr. ${ }^{3}$, \\ Jun-ichi Hamada ${ }^{4}$, and Mitsuhiro Murayama ${ }^{3 *}$ \\ ${ }^{1}$ formerly in the Faculty of Engineering Sciences, Kyushu University, Kasuga, Fukuoka 816-8580, Japan, \\ is now in the Faculty of Engineering, Hokkaido University, Sapporo, Hokkaido 060-8628, Japan. \\ ${ }^{2}$ formerly in Department of Materials Science and Engineering, Virginia Tech, Blacksburg, VA, 24061, \\ is now in Department of Mechanical Engineering, North Carolina A\&T State University, Greensboro, NC, \\ 27411. \\ ${ }^{3}$ Department of Materials Science and Engineering, Virginia Tech, Blacksburg, Virginia 24061. \\ ${ }^{4}$ Nippon Steel \& Sumikin Stainless Steel Corporation, Hikari, Yamaguchi 743-8550, Japan. \\ * Corresponding Author: murayama@vt.edu
}

\begin{abstract}
Niobium-containing ferritic stainless steels are finding new applications in automotive exhaust components because of their oxidation resistance, thermal fatigue resistance, and high-temperature strength. The mechanical behavior of Nb-containing ferritic steels at service temperatures of $973 \mathrm{~K}\left(700^{\circ} \mathrm{C}\right)$ and higher results from the convolution of dynamic microstructural changes including precipitation, precipitate coarsening, strain hardening, recovery, and recrystallization. The relative contributions of these competing processes have yet to be clarified. In this study, the high-temperature flow strength of an $18 \mathrm{Cr}-2 \mathrm{Mo}-0.5 \mathrm{Nb}$ ferritic stainless steel (SUS 444) was correlated with microstructure under different strain and initial precipitate distributions to clarify the relative role of the strengthening and softening processes. High-temperature tensile tests at $1023 \mathrm{~K}\left(750^{\circ} \mathrm{C}\right.$ ) of un-aged (initial
\end{abstract}


microstructure is precipitate-free) and pre-aged (initial microstructure contains precipitates) samples were carried out and transmission electron microscopy was used to assess dislocation distributions and precipitate morphology. The difference in the stress-strain curves between un-aged and pre-aged samples was drastic; the yield strength of the un-aged sample was twice that of the pre-aged sample, and the unaged sample exhibits a noticeable yield drop. Transmission electron microscopy revealed a Laves phase nucleated and grew during the high-temperature tensile test in the un-aged sample and the majority of the precipitates in the pre-aged sample were the same Laves phase. Furthermore, a strain effect on precipitate growth was recognized in un-aged and pre-aged conditions by comparing grip (no strain) and gauge (strained) sections of tensile samples. The dominant strengthening contribution in un-aged samples is initially the precipitate shearing mechanism and it changes to Orowan strengthening beyond the ultimate tensile strength, whereas the dominant contribution in the pre-aged samples appears to be Orowan strengthening throughout the stress-strain curve.

\section{Keywords}

Ferritic stainless steel, high-temperature deformation, precipitation hardening, solution hardening, Laves phase 


\section{Introduction}

Reducing weight and increasing engine efficiency are longstanding goals in the automotive industry. Raising the operating temperature of engine exhaust manifolds and reducing their weight is one component of this strategy. For example, conventional cast iron exhaust manifolds can be replaced by lighter structures made of alloys with excellent thermal fatigue resistance and high-temperature strength. Ferritic stainless steels are candidates for this application. They have good high-temperature oxidation resistance and thermal fatigue resistance, but they suffer from low strength at elevated temperatures compared to austenitic steels. Niobium- $(\mathrm{Nb})$ containing ferritic stainless steels were developed to overcome the lower high-temperature strength [1-3]. Niobium improves high-temperature strength and thermal fatigue resistance by solid-solution hardening and precipitation hardening [4-9]. Fujita et al. [4] reported that fine $\mathrm{Nb}$ carbo-nitrides and Nb-based Laves phase precipitates formed during hightemperature deformation improve the strength of the alloy at $1173 \mathrm{~K}\left(900^{\circ} \mathrm{C}\right)$. Nabiran et al. [5] reported that the contribution due to the rapid coarsening of Laves phase precipitates to the high-temperature strength was comparatively small. On the other hand, it was reported that $\mathrm{Nb}$ forms several different types of precipitates around $900^{\circ} \mathrm{C}$ that could degrade high-temperature strength and thermal fatigue resistance [6]. Morrie et al. [8] noted that rapid coarsening of the Laves phase at high temperatures significantly reduces strength over $973 \mathrm{~K}\left(700^{\circ} \mathrm{C}\right)$, and Sim et al. [9] reported that coarse, rod-shaped Laves phase precipitates $\left(\mathrm{Fe}_{2} \mathrm{Nb}\right)$ formed at $973 \mathrm{~K}\left(700^{\circ} \mathrm{C}\right)$ are very detrimental to high-temperature strength of Nbcontaining steels. With regard to practical applications, there are many studies of the thermal and fatigue behavior [10-13] and the high-temperature deformation behavior [14-17] of high Cr stainless steels. However, the effect of precipitates on the high-temperature deformation mechanism in high Cr stainless steels remains unclear. The present investigation was initiated to clarify the role of precipitates on the high-temperature deformation of high Cr, Nb-containing ferritic stainless steel (18Cr-2Mo-0.5Nb; SUS 444). 


\section{Experimental procedures}

2.1 Material and high-temperature tensile test

The material used in the present study was a $18 \mathrm{Cr}-2 \mathrm{Mo}-0.5 \mathrm{Nb}$ ferritic stainless steel (SUS 444) which was supplied as $2 \mathrm{~mm}$ thick sheet, cold-rolled, solutionized then air-cooled (designated the "unaged” condition). Table I shows the chemical composition of the steel. One of the sheets was heat-treated at $1023 \mathrm{~K}\left(750^{\circ} \mathrm{C}\right)$ for 100 hours to produce coarse, stabilized precipitates. This condition, hereafter termed "pre-aged," is assumed to have a near-equilibrium volume fraction of Laves phase precipitates and a ferritic matrix depleted of $\mathrm{Nb}$ supersaturation. The aging treatment is meant to stabilize the microstructure to changes in matrix supersaturation at high-temperature rather than to increase strength through precipitation. A comparison of high-temperature deformation in un-aged samples (whose microstructure changes dynamically) with pre-aged samples (whose microstructure is comparatively stable) provides a means to investigate contributions to high-temperature strength in the Nb-containing ferritic stainless steel. The grain size of both un-aged and pre-aged samples was about $50 \mu \mathrm{m}$. Tensile specimens with $10 \mathrm{~mm}$ width, $2 \mathrm{~mm}$ thickness and $35 \mathrm{~mm}$ gauge length were prepared from the two conditions (sheets of preaged and of un-aged material). Uniaxial tensile tests were performed at $750^{\circ} \mathrm{C}$ in air with a strain rate of 5 $\times 10^{-5}$ / sec to simulate the service conditions of an automotive exhaust system. Each test specimen was heated to the $1023 \mathrm{~K}\left(750^{\circ} \mathrm{C}\right)$ test temperature at a heating rate of $10 \mathrm{~K}\left(100^{\circ} \mathrm{C}\right) / \mathrm{sec}$. Specimens were held at $1023 \mathrm{~K}\left(750^{\circ} \mathrm{C}\right)$ for $120 \mathrm{sec}$ before the tensile load was applied. To observe the microstructure at intermediate stages of strain, tensile tests were interrupted at various strains before failure and the test pieces were sectioned. The interrupted strains were $0.3 \%, 0.9 \%, 3.0 \%$ and $14.3 \%$. When a tensile test was interrupted, the specimen was cooled to $923 \mathrm{~K}\left(650^{\circ} \mathrm{C}\right)$ at a cooling rate of $10 \mathrm{~K}\left(10^{\circ} \mathrm{C}\right) / \mathrm{sec}$, then and to room temperature by air-cooling. Figure 1 and Table II show the thermo-mechanical history and key for of all the samples and the sample names. 


\subsection{Microstructure observation}

After tensile testing, the tensile specimens were sectioned perpendicular and parallel to the loading axis in two locations: in the gauge region and in the grip section. The grip section reflects the effects of the testing time and temperature on microstructure evolution. On the other hand, the gauge section of the sample undergoes plastic deformation and therefore it reflects the combined effects of the testing time, temperature, and strain on microstructure evolution. The samples were mechanically ground and polished to a thickness of about $50 \mu \mathrm{m}$ and then electro-polished to electron transparency using a $10 \%$ perchloric acid, $90 \%$ methanol solution at $223 \mathrm{~K}\left(-50^{\circ} \mathrm{C}\right), 10 \mathrm{~V}$. The microstructures of these foils were observed using a Philips EM420 TEM (120 kV) and a FEI Titan 300 S/TEM (300 kV). The crystal structure of precipitates in each sample were determined from selected area electron diffraction (SAED) patterns or parallel nano-beam electron diffraction (NBD) patterns. The chemistry of the precipitates was examined by electron dispersive X-ray spectroscopy (EDS) with the FEI Titan 300.

\subsection{Microstructure analysis}

Microstructural characteristics including the precipitate volume fraction and the dislocation density were assessed with imaging software NIH Image J and FEI TIA (Technai Imaging and Analysis). The dispersion parameters, i.e., the precipitate volume fraction, $V_{\mathrm{f}}$, and the average precipitate radius, $r$, were determined by point counting with a superimposed square grid over TEM micrographs. In each sample, about thirty fields of view were analyzed to improve statistical significance. To quantify the dislocation density of each sample, we counted the number of dislocation lines intersecting the foil surface per unit area. To estimate flow stress of un-aged and pre-aged samples, we converted ellipsoidal particles into equivalent spheres of the same volume. The precipitate interparticle spacing, $\lambda$, was bounded by two estimates, $\lambda_{0}$ and $\lambda_{1}$, that were calculated from the precipitate radius and volume 
fractions using the method described in reference [18]. We applied a standard point-counting method, originally developed for optical microscopy, to TEM micrographs with the square grid adjusted to accommodate the scale of the microstructure [29]. In general, $\lambda$ is equal to $\lambda_{0}$ when the particles are strong dislocation obstacles, while $\lambda_{0}<<\lambda<\lambda_{1}$, when the particles act as weak obstacles. In this study, the inter-particle spacing of the strongest obstacles, $\lambda_{0}$, and the spacing of the weakest obstacles, $\lambda_{1}$, were calculated using the relationships [18]:

$$
\begin{gathered}
\lambda_{0}=\sqrt{\frac{2 \pi}{3 V_{\mathrm{f}}}} r \\
\lambda_{1}=\frac{4 r}{3 V_{\mathrm{f}}}
\end{gathered}
$$

\section{Results}

3.1 High-temperature tensile behavior at $750^{\circ} \mathrm{C}$

Figure 2 shows typical engineering stress-strain curves of un-aged and pre-aged SUS 444 at $1023 \mathrm{~K}\left(750^{\circ} \mathrm{C}\right)$. The high-temperature deformation behavior of the two kinds of samples is remarkably different. The yield stress and the ultimate tensile stress of the un-aged condition are approximately a factor of two greater than those of pre-aged material. In addition, a yield drop occurs in the un-aged material at $0.9 \%$ strain. As will be noted in more detail later, the lower strength, pre-aged material initially contains a high density of Laves precipitates, whereas the higher-strength un-aged material is comparatively free of precipitates at the beginning of tensile testing. Generally speaking, a high density of precipitates is expected to increase tensile strength relative to a precipitate-free microstructure, but the opposite trend is observed between the un-aged and pre-aged material. 
3.2 Microstructure of pre-aged and un-aged grip samples; i.e., no plastic strain (PA-GR, UA-GR)

TEM images of PA-GR and UA-GR samples are shown in Figure 3. Many rod-like precipitates were observed in the PA-GR1 and PA-GR3, whereas only a few fine precipitates were found in UA-GR1, and block-like precipitates were observed in UA-GR2. Figure 4 shows the precipitate characteristics of PA-GR2. SAED patterns (Figures 4 (b)-(e)) were obtained from points A-D, respectively, in the HAADF-STEM image of Figure 4 (a). Analyzing the SAED patterns of Figures 4 (c)-(e) revealed all the precipitates are $\mathrm{Fe}_{2} \mathrm{Nb}$ type Laves phase. Figure 4 (f) shows the chemical composition (at\%) of points AD by EDS analysis. Points B-D indicate the presence of $\mathrm{Cr}$ and Mo, so we suppose these elements substitute for $\mathrm{Fe}$ and $\mathrm{Nb}$ in the Laves structure, that is, $(\mathrm{Fe}, \mathrm{Cr})_{2}(\mathrm{Nb}, \mathrm{Mo})$. As can be seen by comparing Figures 3 (a) and (b), the shape of the Laves precipitates change from a fine, block-like appearance to a more rod-like morphology during annealing at $1023 \mathrm{~K}\left(750^{\circ} \mathrm{C}\right)$. Sawatani et al. [19] observed similar Laves phase precipitates with block-like and rod-like shapes in an aged Fe-19Cr-2Mo steel.

The precipitate dispersion parameters in the pre-aged and the un-aged grip samples are shown in Table III. In the pre-aged grip samples (PA-GR1 and PA-GR3), the average diameter and the precipitate volume fraction were similar (Figure 3 (a) and (b)). Evidently, the brief period of time at temperature during the tensile test was too short to cause significant precipitate coarsening once the alloying element supersaturation was removed by the pre-aging treatment. Consequently, the microstructure of PA-GR1 and that of PA-GR3 were qualitatively the same. In the un-aged sample (UA-GR1, Figure 3 (c)), a few fine precipitates were present on dislocations within the grain interiors after $60 \mathrm{sec}$ at the $1023 \mathrm{~K}\left(750^{\circ} \mathrm{C}\right)$ testing temperature. As the time at temperature increased to 2860 sec (UA-GR2), the volume fraction of the Laves precipitates increased drastically, and precipitates formed on grain boundaries and within grain interiors. A grain boundary heavily decorated by precipitates is apparent in Figure 3 (d). 
3.3 Microstructure of pre-aged and un-aged gauge samples; i.e., subjected to plastic strain (PA-GA, UAGA)

Figure 5 and Figure 6 show TEM images of PA-GA and UA-GA samples, respectively. The precipitates dispersion parameters of precipitates and the dislocation density in PA-GA and UA-GA samples are also shown in Table IV.

Numerous dislocation tangles were observed in the pre-aged gauge sample after a plastic strain of only 0.3\% (PA-GA1), Figure 5 (a). As high-temperature deformation increased to a strain of 3\% (PAGA2), the dislocation density decreased (Figure 5 (b)). The dislocation density remained low with further deformation up to $14.3 \%$ strain, and serrated boundaries appeared with dislocation walls and many subgrain boundaries (PA-GA3, Figure 5 (c)). This sequence of observations can be explained by concurrent work hardening and recovery/recrystallization during the high-temperature deformation. A decrease in dislocation density during deformation suggests recovery processes taking place faster than work hardening processes (from $0.3 \%$ to $3 \%$ strain). The relatively stable dislocation density that follows from $3 \%$ to $14.3 \%$ strain implies a steady state is achieved between the competing tendencies of work hardening and recovery. In addition, the dislocation rearrangement, annihilation, and absorption by grain boundaries during recovery processes, is often accompanied simultaneously by the formation of serrated boundaries [20]. From these observations, we conclude the dislocation density increased from work hardening at the beginning of tensile test, and then it decreased and reached a constant value when hightemperature steady state deformation and continuous recovery/recrystallization processes were balanced.

In the un-aged gauge sample at $0.3 \%$ strain (UA-GA1), very small precipitates about $20 \mathrm{~nm}$ in diameter are seen on dislocations, Figure 6 (a). These were also identified as a Laves phase. Comparing this microstructure with that in the grip (UA-GR1, Figure 3 (c)), it is evident the number density of the Laves precipitates in UA-GA1 is much higher than that in UA-GR1. Since plastic strain is the only difference between samples UA-GA1 and UG-GR1, the nucleation of the precipitates on dislocations in 
Figure 6 (a) must be a strain-induced phenomenon. The precipitates in UA-GA1 had the smallest diameter and the smallest inter-particle spacing so they could be most effective at pinning dislocation motion. Figure 6 (b) shows the Laves precipitates coarsened and their volume fraction increased as the tensile strain increased to $0.9 \%$ (UA-GA2). If dispersion hardening (precipitation hardening) is the dominant strengthening mechanism, the microstructure of UA-GA1 should have the highest flow stress because it has the finest Laves phase precipitates uniformly dispersed in the matrix. However, this is not the case; UA-GA2 has the highest flow stress. It can be inferred from this that other strengthening mechanisms are responsible for the initial flow strength of un-aged samples. In Figure 6 (c), deformation to 3.0\% (UA-GA3) resulted in further coarsening of Laves precipitates and led to a decrease in flow stress. The general trend in the precipitate size - flow stress relationship matches that reported by Sim et al. [9], with the exception of the $0.3 \%$ strain. They reported that fine Laves precipitates improved hightemperature strength of $\mathrm{Nb}$-containing steels but coarse Laves precipitates decreased high-temperature strength. In the present work, large block-like (coarse) Laves precipitates were observed in the lowest strength UA-GA3 sample but were not observed in the other un-aged strained samples. Thus, the coarse, block-like Laves precipitates, when they are present, are associated with lower high-temperature strengths.

\section{Discussion}

4.1 Relationship between tensile strength and microstructure

For high-temperature deformation in which dispersion hardening (precipitation hardening) plays a role, moving dislocations are obstructed by the dispersed particles on the slip planes. If the particles are harder than the matrix, the yield strength can be nearly equal to the Orowan stress. The Orowan stress, $\sigma_{\text {or }}$, is estimated from the equation [18],

$$
\sigma_{\mathrm{or}}=\frac{M G b}{\lambda}
$$


where $G$ is the shear modulus, $M$ is the Taylor factor, $b$ is the Burgers vector and $\lambda$ is the inter particle spacing. The Orowan stress for the microstructures under consideration can be estimated from $\lambda_{0}$ or $\lambda_{1}$ values calculated from particle radius and volume fraction measurements in the pre-aged and the un-aged samples. The measured flow stresses then can be compared with the calculated Orowan stresses. If a calculated Orowan stress greatly exceeds the observed flow stress for a particular microstructure, it can be concluded that Orowan strengthening is not operative. Table V compares measured flow stresses with the Orowan stresses, $\sigma_{\text {oro }}$ and $\sigma_{\text {or } 1}$, calculated from inter-particle spacings, $\lambda_{0}$ and $\lambda_{1}$ (Eqs. (1) and (2)), respectively. The Orowan stress estimated from $\lambda_{0}$ was unrealistically large relative to the measured flow stress indicating the Laves precipitates cannot be acting as ideal hard obstacles. Consequently, we focus on comparing $\sigma_{\text {or1 }}$ with either the measured flow stress or the yield strength.

In the grip section samples at $0.3 \%$ strain (PA-GR1 and UA-GR1), the values of the calculated $\square_{\mathrm{r} 1}$ are 40.2 and $47.6 \mathrm{MPa}$, respectively. The yield strength of these samples estimated from the stressstrain curves (Figure 2) are $45 \mathrm{MPa}$ and $100 \mathrm{MPa}$, respectively. Thus, agreement between $\sigma_{\text {or1 }}$ and the yield strength is reasonable for the pre-aged condition, but not for the un-aged condition.

In the gauge section of the un-aged samples, the values of $\sigma_{\text {or1 }}$ calculated for UA-GA1 and UAGA2 are about $486 \mathrm{MPa}$ and $103 \mathrm{MPa}$, respectively (Table V). The former is much higher than the measured flow stress (100 MPa), whereas the latter is in reasonable agreement with the measured flow stress (112 MPa). From these comparisons, it is evident that the Orowan mechanism is consistent with the observed high-temperature strength in the pre-aged condition but not in the un-aged condition. This supposition is supported by Figure 7, which shows numerous dislocation loops around a single Laves phase precipitate in a pre-aged, $14.3 \%$ strained sample.

In the un-aged condition (UA-GA1, Figure 6 (a)), there are many small precipitates within ferrite grains. At the initial stage of tensile testing un-aged samples, the matrix is supersaturated with solute and the precipitates are small; we assume the precipitates are partially coherent with the matrix and below the 
critical size for particle shearing by moving dislocations. If accurate, particle shearing and solid-solution hardening would be the dominant strengthening mechanisms until the maximum flow stress is achieved (at $0.9 \%$ strain); the Orowan strengthening expression would not be applicable in this situation. Further study is necessary to confirm whether dislocations do in fact shear the smaller Laves precipitates (20 nm in diameter), but this scenario is a plausible explanation for why the predicted Orowan stress applies to pre-aged microstructures but not for the initial high-temperature strength of un-aged microstructures.

\subsection{High-temperature yield point phenomenon}

A drop in flow stress of nearly $50 \%$ occurred at $0.9 \%$ strain in samples in the un-aged condition. Horiuchi and Yoshinaga reported a similar yield drop in Al-Mg and Al-Cu alloys and associated it with a solute drag on edge dislocations from solute atmospheres around the dislocations [21]. They attributed the solute atmospheres to the size difference between solvent $(\mathrm{Al})$ and solute $(\mathrm{Mg}$ or $\mathrm{Cu}$ ) atoms, and it was reported the flow stress and the yield drop increase considerably with the solute concentration. Nakashima et al. [22] reported that the high-temperature yield point phenomenon also occurs in alloys in which solid-solution and dispersion strengthening coexist (e.g. Al-Mg-Mn alloy). Oliver and Nix [23] studied the high-temperature strength of an Al-Mg alloy containing dispersed particles of $\mathrm{Al}_{2} \mathrm{O}_{3}$ and $\mathrm{MgO}$ and reported that the yield drop phenomenon resulted from particle coarsening. In SUS444, it is likely that similar yield point contributions result from atmospheres of solute (Mo, $\mathrm{Nb}$ ) atoms in iron and from Laves precipitate coarsening. At the beginning of high-temperature deformation of un-aged samples in our study, the solute elements $\mathrm{Nb}$ and Mo are dissolved and supersaturated in the ferrite matrix. Since the volume fraction of precipitates in UA-GA2 is significantly larger than that in UA-GA1 and about the same as that in UA-GA3, it is inferred that strain-induced solute precipitation is effectively complete by 0.9\% strain. At this point, solid solution hardening from matrix supersaturation becomes negligible (a small amount may remain from equilibrium solute solubility) and the dominant strengthening 
contributions switch from particle shearing and solid-solution strengthening to Orowan strengthening. The early drop in flow stress of un-aged samples is consistent with an earlier assessment of a reduction of high-temperature strength in Nb-containing steels caused by Laves precipitation [9]. As discussed below, the subsequent decrease in flow stress is largely a consequence of precipitate coarsening.

\subsection{Strain effect on precipitate coarsening}

Figure 8 plots data from Tables III and IV to show how strain and the time at testing temperature affect the average diameter of precipitates in the pre-aged and the un-aged samples. The effect of strain is found by comparing trends of triangle data points (strain-free grip samples) with the trends of circular data points (plastically strained gauge samples). In both pre-aged and un-aged samples, the average precipitate diameter is substantially greater in the gauge portion of the tensile specimens than in the grip section. Thus, strain-induced growth and coarsening of precipitates took place in both pre-aged and un-aged samples. In particular, the coarsening rate in the un-aged gauge sample is the highest among the four types of sample. The volume fraction of precipitates in the un-aged gauge sample $(0.3 \%$ strain, $60 \mathrm{sec}, \mathrm{UA}-\mathrm{GA} 1$ ) is about 8 times higher than that in the un-aged grip sample (no strain, 60 sec, UAGR1; see Tables III and IV). In UA-GA1, many dislocations are evident within grains as can be seen in Figure 6 (a). These dislocations could serve as heterogeneous nucleation sites for Laves phase precipitates. The dislocation density, which is affected by both strain and the rate of recovery at $750^{\circ} \mathrm{C}$, drops at $0.9 \%$ strain (UA-GA2) and remains unchanged until 3.0\% strain (UA-GA3), while the volume fraction of Laves phase is almost constant from UA-GA2 to UA-GA3. From these results, we conclude the Laves phase nucleates and grows until $0.9 \%$ strain after which only coarsening takes place.

The coarsening rate of precipitates can be calculated using Ostwald ripening expressions [24, 25].

$$
r^{3}-r_{0}^{3}=K_{p} t, \quad K_{p}=\frac{8 \gamma D C_{e} V_{m}^{2}}{9 R T}
$$


where $r$ is the average particle radius, $r_{0}$ is the initial average particle radius, $\gamma$ is the interfacial energy, $D$ is the diffusion coefficient, $C_{\mathrm{e}}$ is the equilibrium solute concentration, $V_{\mathrm{m}}$ is the molar volume of the particle, $R$ is the gas constant and $T$ is the absolute temperature. We assume the controlling diffusivity for coarsening of the Laves phase precipitates is that of $\mathrm{Nb}$ in ferrite because the diffusion coefficient of carbon and nitrogen $\left(1.04 \times 10^{-10}\right.$ and $1.28 \times 10^{-10} \mathrm{~m}^{2} \mathrm{~s}^{-1}$, respectively) are five to seven orders of magnitude greater than that of $\mathrm{Nb}\left(5.40 \times 10^{-16} \mathrm{~m}^{2} \mathrm{~s}^{-1}\right)$, and the diffusion coefficient of $\mathrm{Fe}\left(9.15 \times 10^{-17}\right.$ $\mathrm{m}^{2} \mathrm{~s}^{-1}$ ) is similar to that of $\mathrm{Nb}$ [26]. Figure 9 shows the relationship between $r^{3}-r_{0}^{3}$ and time for the unaged samples. The slope of the plot is $K_{\mathrm{p}}$. The value of $K_{\mathrm{p}}$ for the un-aged gauge sample is about 25 times larger than that of the un-aged grip sample. The interfacial energy, the equilibrium solute concentration and the molar volume of particles in both samples are identical, so the difference between the coarsening rates of the two types of samples may be caused by a difference in the effective diffusion coefficient. In the un-aged gauge sample, many dislocations were observed so they may effectively increase the diffusivity of $\mathrm{Nb}$ through pipe diffusion relative to the un-aged grip sample.

The estimated Orowan stresses of UA-GA2 and UA-GA3 are similar to the measured flow stresses in Table V. Comparing the microstructure of UA-GA2 with that of UA-GA3, the dislocation densities are almost same, but the average diameter of precipitates in UA-GA3 is much larger than that in UA-GA2. Therefore, we conclude precipitate coarsening causes the decrease of flow stress between these strain states.

In the high-temperature deformation of dispersion / precipitation strengthened alloys, it often has been reported that the flow stress gradually decreases as the deformation proceeds over a wide range of strains [22, 23], and precipitate coarsening [27, 28] during deformation is considered to be the main mechanism responsible for this decrease. The flow stress trends and microstructure evolution in the samples of the present study are consistent with this view. 


\section{Conclusions}

The present study examined high-temperature deformation and microstructures of un-aged and pre-aged 18Cr-2Mo-0.5Nb (SUS 444) ferritic stainless steel to clarify the effect of precipitates on the high-temperature strength. The following conclusions were drawn:

(1) The high-temperature tensile deformation behaviors of the pre-aged and the un-aged samples were very different. In the un-aged sample, the significant drop in flow stress beyond $0.9 \%$ strain may have a contribution from solute drag on dislocations, but the significant reduction of supersaturation at this strain indicates precipitate coarsening is the predominant cause of the drop.

(2) In the un-aged samples, Laves phase precipitates nucleated and grew during the high-temperature tensile test, and plastic strain accelerated the precipitation process. Strain-induced coarsening of precipitates occurred in both pre-aged and un-aged samples.

(3) The high-temperature strength of un-aged samples is initially a combination of solid-solution strengthening plus particle shearing. Near the peak flow stress (0.9\% strain), the strengthening mechanism switches to Orowan strengthening. In the pre-aged samples, however, the strengthening mechanism is Orowan strengthening throughout the deformation process.

\section{Acknowledgements}

The authors are grateful to the Nanoscale Characterization and Fabrication Laboratory of the Institute for Critical Technology and Applied Science (NCFL-ICTAS) at Virginia Tech for the use of its facilities. K.I. thanks Professor Hideharu Nakashima in Kyushu University for fruitful discussions. K.I. was partly supported by Strategic Young Researcher Overseas Visits Program (JSPS \#R2408, Japan). 


\section{References}

[1] S. Nakamura, K. Miyakusu and Y. Uematsu: Current advances in materials and processes - the Iron and Steel Institute of Japan, 1991, vol. 4, pp. 1788-91.

[2] K. Ohmura, N. Fujita, M. Kikuchi, T. Tsuzaki and I. Hiroshige: Current advances in materials and processes - the Iron and Steel Institute of Japan, 1991, vol. 4, pp. 1796-99.

[3] N. Fujita, K. Ohmura, M. Kikuchi, T. Suzuki, S. Funaki and I. Hiroshige: Scripta Mater., 1996, vol. 35, pp. 705-10.

[4] N. Fujita, K. Ohmura and A. Yamamoto: Mater. Sci. Eng. A, 2003, vol. 351, pp. 272-81.

[5] N. Nabiran, S. Klein, S. Weber, and W. Theisen: Metall. Mater. Trans. A, 2015, vol. 46A, pp. 102-14.

[6] A. Miyazaki, K. Takao and O. Furukimi: ISIJ International, 2002, vol. 42, pp. 916-20.

[7] N. Fujita and M. Kikuchi: Tetsu-to-Hagané, 2003, vol. 89, pp. 510-17.

[8] D. G. Morris, M. A. Munoz-Morris and C. Baudin: Acta Mater. 2004, vol. 52, pp. 2827-36.

[9] G. M. Sim, J. C. Ahn, S. C. Hong, K. J. Lee and K. S. Lee: Mater. Sci. Eng. A, 2005, vol. 396, pp. 159-65.

[10] Y. Uematsu, M. Akita, M. Nakajima and K. Tokaji: Int. J. Fatigue, 2008, vol. 30, pp. 642-48.

[11] T. Yamagishi, M. Akita, M. Nakajima, Y. Uematsu and K. Tokaji: Procedia Engineering, 2010, vol. 2, pp. 275-81.

[12] S. J. Ko and Y-J. Kim: Mater. Sci. Eng. A, 2012, vol. 534, pp. 7-12.

[13] Y-T. Chiu and C-K. Lin: J. Power Sources, 2012, vol. 219, pp. 112-19.

[14] Z. Y. Liu, F. Gao, L. Z. Jiang and G. D. Wang: Mater. Sci. Eng. A, 2010, vol. 527, pp. 3800-6. 
[15] Y-T. Chiu, C-K. Lin and J-C. Wu: J. Power Sources, 2011, vol. 196, pp. 2005-12.

[16] Y-T. Chiu and C-K. Lin: J. Power Sources, 2012, vol. 198, pp. 149-57.

[17] S. V. Mehtonen, L. P. Karjalainen and D. A. Porter: Mater. Sci. Eng. A, 2013, vol. 571, pp. 1-12.

[18] M. Kato: Introduction to the theory of dislocations, pp. 139-144, Shokabo, Tokyo, 1999.

[19] T. Sawatani, S. Minamino and H. Morikawa: Trans. ISIJ, 1982, vol. 22, pp. 172-80

[20] F. J. Humphreys and M. Hatherly: RECRYSTALLIZATION and Related Annealing Phenomena Second Edition, pp. 451-467, ELSEVIER, UK, 2004.

[21] R. Horiuchi and H. Yoshinaga: Trans. JIM, 1965, vol. 6, pp. 131-38.

[22] H. Nakashima, K. Iwasaki, S. Goto and H. Yoshinaga: Marer. Trans. JIM, 1990, vol. 31, pp. 35-45.

[23] W. C. Oliver and W. D. Nix: Acta Metall., 1982, vol. 30, pp. 1335-47.

[24] I. M. Lifshitz and V. V. Slyozov: J. Phys. Chem. Solids, 1961, vol. 19, pp. 35-50.

[25] C. Wagner: Z. Electrochem., 1961, vol. 65, pp. 581-91.

[26] E. A. Brandes and G. B. Brook: Smithells Metals Reference Book Seventh Edition, pp. 13-19 - 13-20, Butterworth - Heinernann, Read Educational and Professional Publishing, UK, 1998.

[27] R. S. W. Shewfelt and L. M. Brown: Phil. Mag. 1974, vol. 30, pp. 1135-45.

[28] R. S. W. Shewfelt and L. M. Brown: Phil. Mag. 1977, vol. 35, pp. 945-62.

[29] G. F. Vander Voot: Metallography, Principles and Practice, McGraw Hill, NY, 1984. 


\section{List of Tables:}

Table I Chemical composition of SUS444 stainless steel (mass\%).

Table II SUS 444 sample key and thermo-mechanical history.

Table III Precipitates dispersion parameters in pre-aged and un-aged grip SUS444 samples.

Table IV Precipitates dispersion parameters in pre-aged and un-aged gauge SUS444 samples.

Table V Orowan stress of SUS444 pre-aged and un-aged samples calculated from inter-particle spacing. 


\section{Figure captions:}

Figure 1 Thermo-mechanical history of SUS 444 samples.

Figure 2 Stress-strain curves of pre-aged and un-aged SUS444 samples at $750^{\circ} \mathrm{C}$.

Figure 3 TEM images of pre-aged and un-aged grip SUS444 samples: (a) PA-GR1, (b) PA-GR3, (c) UA-GR1 and (d) UA-GR2.

Figure 4 EDS analysis of precipitates and matrix in PA-GR2: (a) HAADF-STEM image, (b)-(e) SAED patterns from points A-D, and (f) chemical composition (at\%) of points A-D.

Figure 5 TEM images of pre-aged gauge SUS444 samples: (a) PA-GA1 (0.3\%), (b) PA-GA2 (3.0\%) and (c) PA-GA3 (14.3\%).

Figure 6 TEM images of un-aged gauge SUS444 samples: (a) UA-GA1 (0.3\%), (b) UA-GA2 (0.9\%) and (c) UA-GA3 (3.0\%).

Figure 7 TEM image of dislocation loops around Laves precipitate in PA-GA3.

Figure 8 Time and strain effects on average diameter of precipitates in pre-aged and un-aged samples.

Figure 9 Relationship between the cube of average size of precipitates and time in un-aged grip and gauge samples. 
Table I

Chemical composition of SUS444 stainless steel (mass\%).

\begin{tabular}{lllllllllll}
\hline $\mathrm{C}$ & $\mathrm{Si}$ & $\mathrm{Mn}$ & $\mathrm{P}$ & $\mathrm{S}$ & $\mathrm{Cr}$ & $\mathrm{Mo}$ & $\mathrm{Nb}$ & $\mathrm{Ti}$ & $\mathrm{N}$ & $\mathrm{Fe}$ \\
\hline 0.005 & 0.35 & 0.99 & 0.03 & 0.001 & 18.4 & 1.8 & 0.48 & 0.10 & 0.012 & Bal. \\
\hline
\end{tabular}


Table II

SUS 444 sample key and thermo-mechanical history.

\begin{tabular}{|c|c|c|c|c|c|c|}
\hline & & $\begin{array}{l}\text { Sample } \\
\text { name }\end{array}$ & $\begin{array}{l}\text { Strain } \\
(\%)\end{array}$ & $\begin{array}{l}\text { Testing } \\
\text { time (sec) }\end{array}$ & $\begin{array}{r}\text { Aging time } \\
\text { (sec) }\end{array}$ & $\begin{array}{r}\text { Total holding } \\
\text { time at } 750^{\circ} \mathrm{C} \\
(\mathrm{sec})\end{array}$ \\
\hline \multirow[t]{6}{*}{ pre-aged } & \multirow{3}{*}{$\begin{array}{l}\text { grip } \\
\text { (un-strained) }\end{array}$} & PA-GR 1 & - & 60 & 360000 & 360180 \\
\hline & & PA-GR 2 & - & 600 & 360000 & 360600 \\
\hline & & PA-GR 3 & - & 2860 & 360000 & 362980 \\
\hline & \multirow{3}{*}{$\begin{array}{l}\text { gage } \\
\text { (strained) }\end{array}$} & PA-GA 1 & 0.3 & 60 & 360000 & 360180 \\
\hline & & PA-GA 2 & 3.0 & 600 & 360000 & 360720 \\
\hline & & PA-GA 3 & 14.3 & 2860 & 360000 & 362980 \\
\hline \multirow[t]{5}{*}{ un-aged } & \multirow{2}{*}{$\begin{array}{l}\text { grip } \\
\text { (un-strained) }\end{array}$} & UA-GR 1 & - & 60 & 0 & 180 \\
\hline & & UA-GR 2 & - & 2860 & 0 & 2980 \\
\hline & \multirow{3}{*}{$\begin{array}{l}\text { gage } \\
\text { (strained) }\end{array}$} & UA-GA 1 & 0.3 & 60 & 0 & 180 \\
\hline & & UA-GA 2 & 0.9 & 180 & 0 & 300 \\
\hline & & UA-GA 3 & 3.0 & 600 & 0 & 720 \\
\hline
\end{tabular}


Table III

Precipitates dispersion parameters in pre-aged and un-aged grip SUS444 samples.

\begin{tabular}{lrrr}
\hline & Time, $t$ (sec) & $\begin{array}{c}\text { Volume fraction of } \\
\text { precipitates, } \\
V_{\mathrm{f}}(\%)\end{array}$ & $\begin{array}{c}\text { Average diameter of } \\
\text { precipitates, }\end{array}$ \\
\hline PA-GR1 & 60 & 4.92 & $2 r(\mathrm{~nm})$ \\
PA-GR3 & 2860 & 5.35 & 268 \\
\hline UA-GR1 & 60 & 0.63 & 313 \\
UA-GR2 & 2860 & 4.61 & 29 \\
\hline
\end{tabular}


Table IV

Precipitates dispersion parameters in pre-aged and un-aged gage SUS444 samples.

\begin{tabular}{lrrrr}
\hline & $\begin{array}{l}\text { Strain, } \\
\varepsilon(\%)\end{array}$ & $\begin{array}{c}\text { Volume fraction of } \\
\text { precipitates, } \\
V_{\mathrm{f}}(\%)\end{array}$ & $\begin{array}{c}\text { Average diameter of } \\
\text { precipitates, } \\
2 r(\mathrm{~nm})\end{array}$ & $\begin{array}{c}\text { Dislocation density, } \\
\text { PA-GA1 }\end{array}$ \\
\hline PA-GA2 & 3.3 & 4.58 & 412 & $\rho\left(\mathrm{m}^{-2}\right)$ \\
PA-GA3 & 14.3 & 4.43 & 402 & $2.02 \times 10^{13}$ \\
\hline UA-GA1 & 0.3 & 4.74 & 393 & $3.31 \times 10^{12}$ \\
UA-GA2 & 0.9 & 4.88 & 22 & $1.77 \times 10^{13}$ \\
UA-GA3 & 3.0 & 6.12 & 130 & $5.02 \times 10^{12}$ \\
\hline
\end{tabular}


Table V

Orowan stress of SUS444 pre-aged and un-aged samples calculated from inter-particle spacing.

\begin{tabular}{|c|c|c|c|c|c|}
\hline & $\mathrm{Eq}$ & (1) & Eq. & (2) & \\
\hline & $\begin{array}{l}\text { Strongest inter- } \\
\text { particle spacing, } \\
\lambda_{0}(\mu \mathrm{m})\end{array}$ & $\begin{array}{l}\text { Orowan stress, } \\
\qquad \sigma_{\mathrm{or} 0}(\mathrm{MPa})\end{array}$ & $\begin{array}{l}\text { Weakest inter- } \\
\text { particle spacing, } \\
\lambda_{1}(\mu \mathrm{m})\end{array}$ & $\begin{array}{c}\text { Orowan stress, } \\
\sigma_{\text {or1 }}(\mathrm{MPa})\end{array}$ & $\begin{array}{l}\text { Mleasured } \\
\text { flow stress } \\
\text { (MPa) }\end{array}$ \\
\hline PA-GR1 & 0.87 & 166.9 & 3.63 & 40.2 & N/A \\
\hline PA-GR2 & 0.98 & 149.0 & 3.90 & 37.4 & N/A \\
\hline PA-GA1 & 1.39 & 104.8 & 6.00 & 24.3 & 45 \\
\hline PA-GA2 & 1.38 & 105.6 & 6.05 & 24.1 & 45 \\
\hline PA-GA3 & 1.31 & 111.7 & 5.53 & 26.4 & 42 \\
\hline UA-GR1 & 0.26 & 551.9 & 3.07 & 47.6 & N/A \\
\hline UA-GR2 & 0.31 & 470.6 & 1.33 & 109.7 & N/A \\
\hline UA-GA1 & 0.07 & 2024.9 & 0.30 & 485.5 & 100 \\
\hline UA-GA2 & 0.38 & 383.8 & 1.42 & 103.0 & 112 \\
\hline UA-GA3 & 0.46 & 314.1 & 1.77 & 82.3 & 65 \\
\hline
\end{tabular}



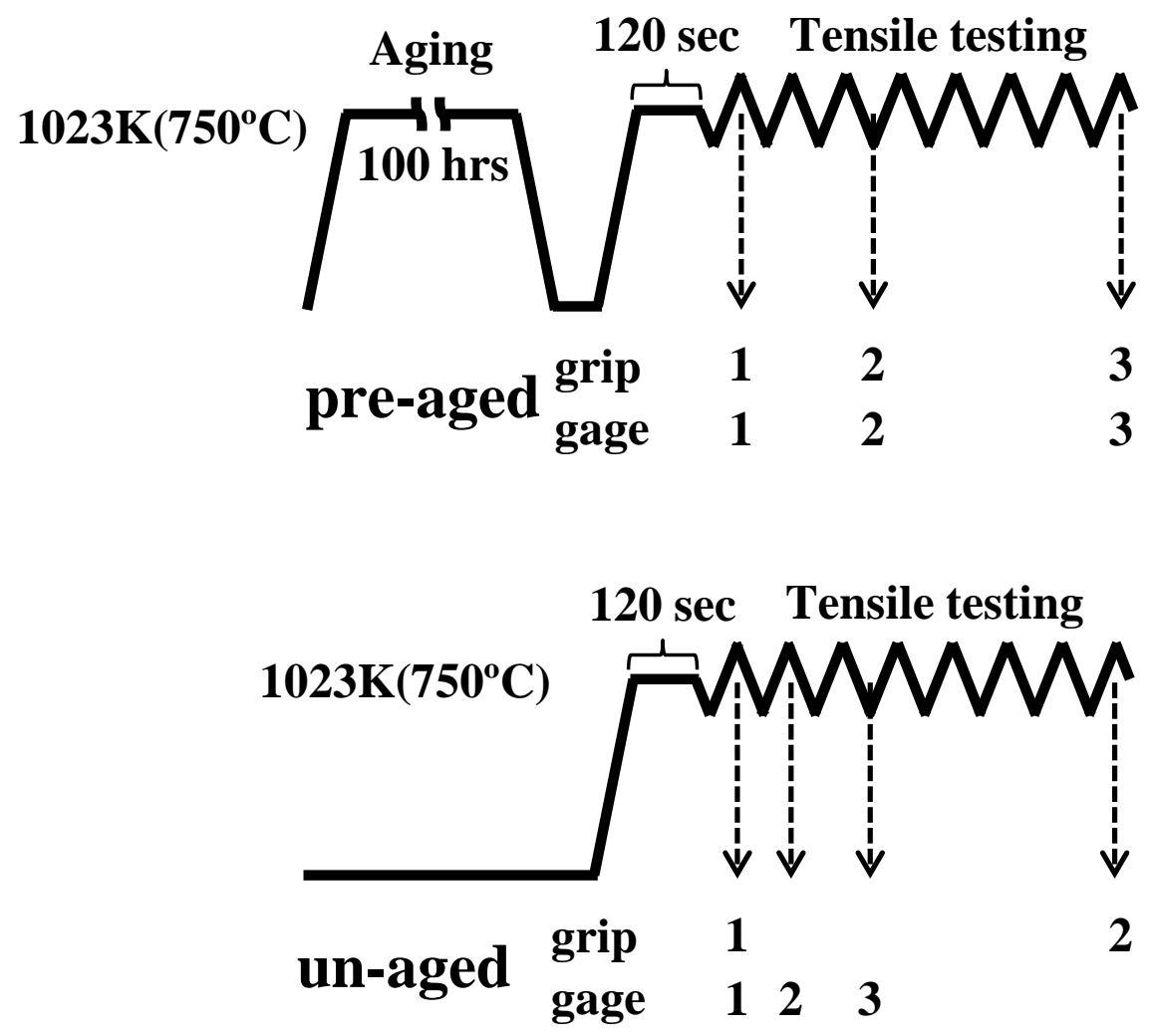

Fig. 1 Thermo-mechanical history of SUS 444 samples. 


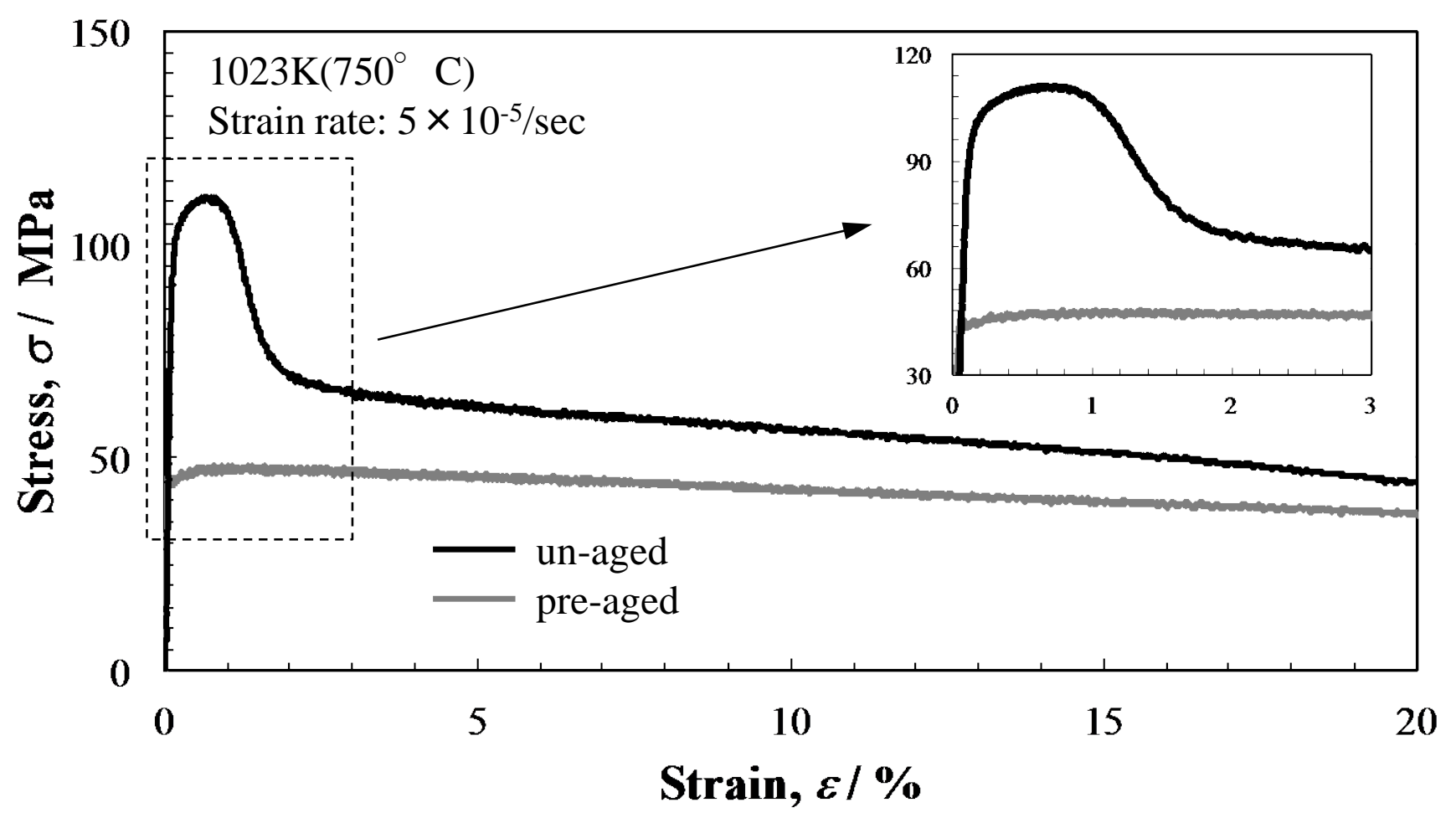

Fig. 2 Stress-strain curves of pre-aged and un-aged SUS444 samples at $750^{\circ} \mathrm{C}$. 

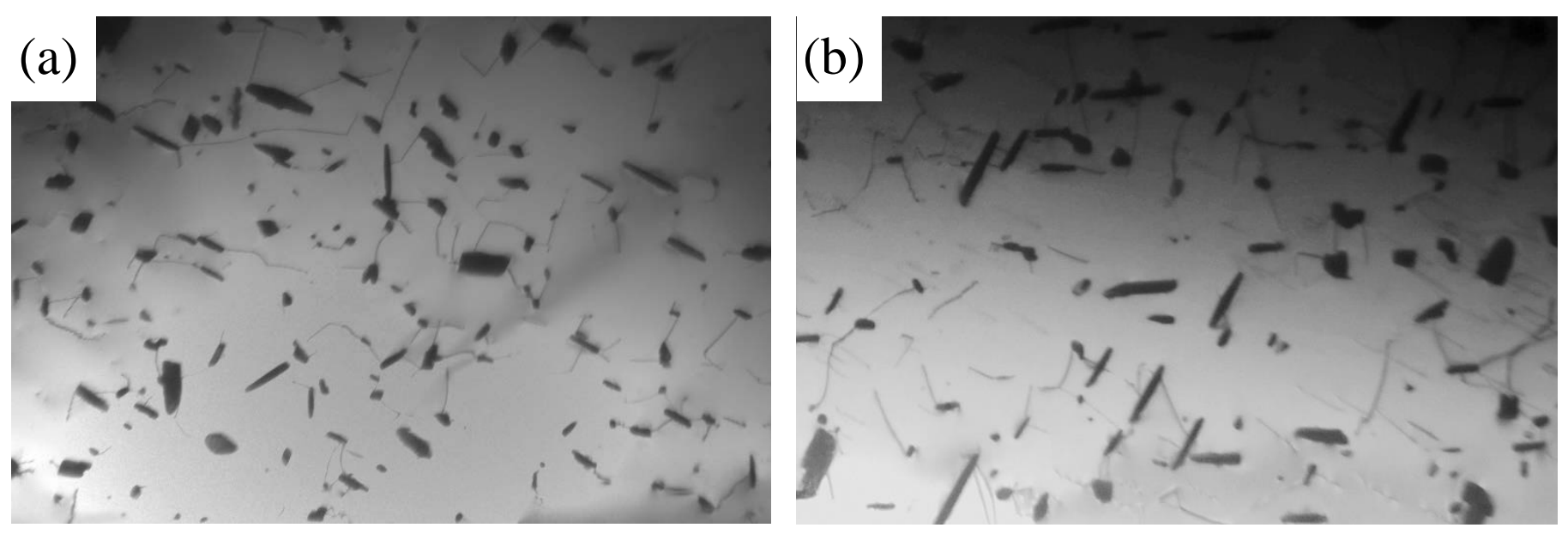

(c)

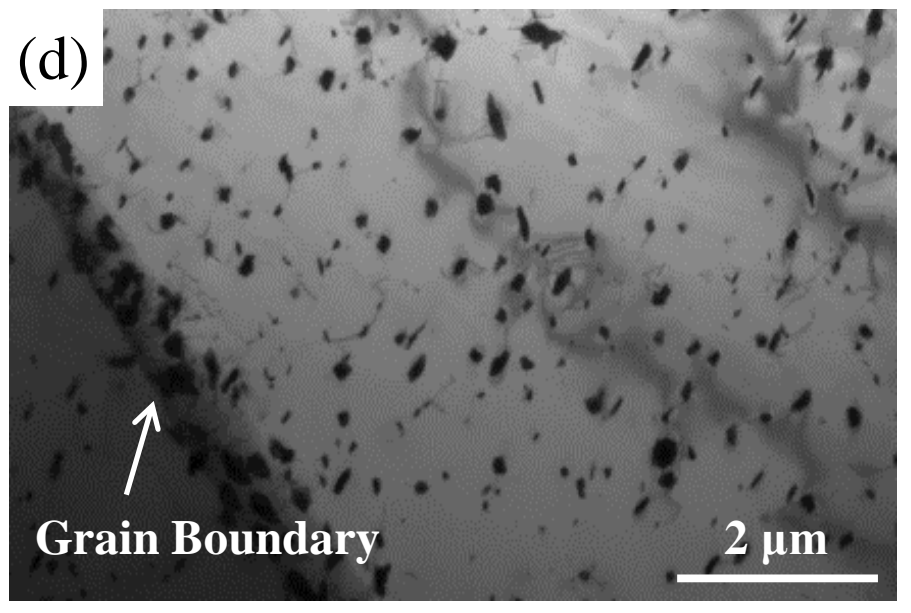

Fig. 3 TEM images of pre-aged and un-aged grip SUS444 samples: (a) PA-GR1, (b) PA-GR3, (c) UA-GR1 and (d) UA-GR2. 
(a)

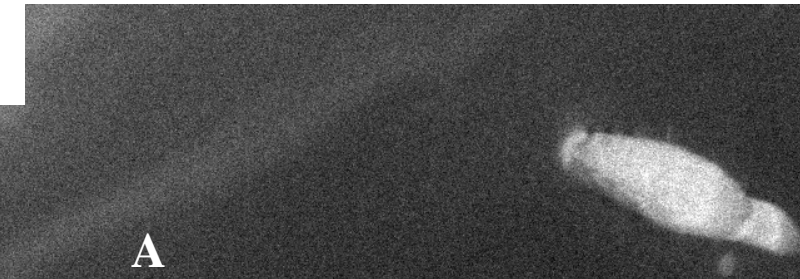

$\mathbf{A}$
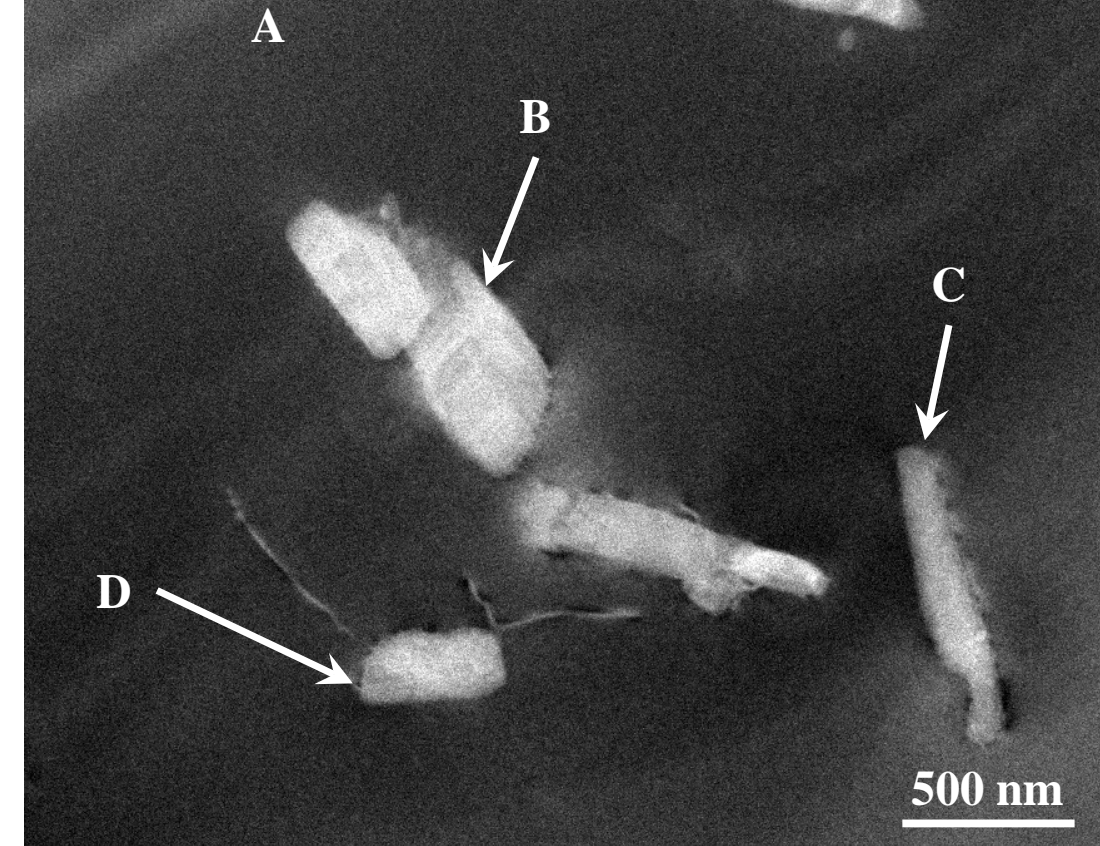

(C)

(d)

(e)

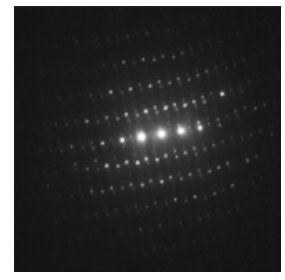

(f)

$\square \mathrm{Fe} \quad \mathrm{Cr} \quad \mathrm{Nb} \square$ Mo $\square$ Others

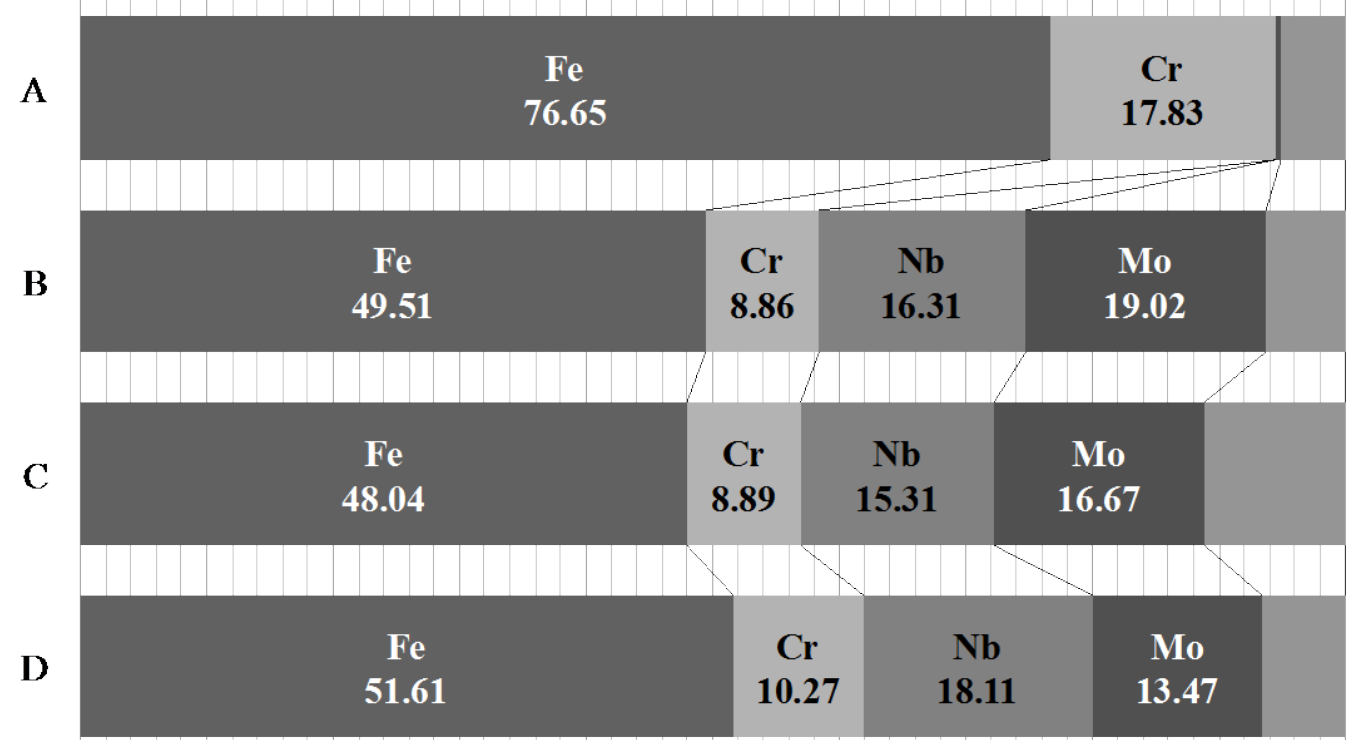

Fig. 4 EDS analysis of precipitates and matrix in PA-GR2: (a) HAADF-STEM image, (b)-(e) SAED patterns from points A-D, and (f) chemical composition (at\%) of points A-D. 

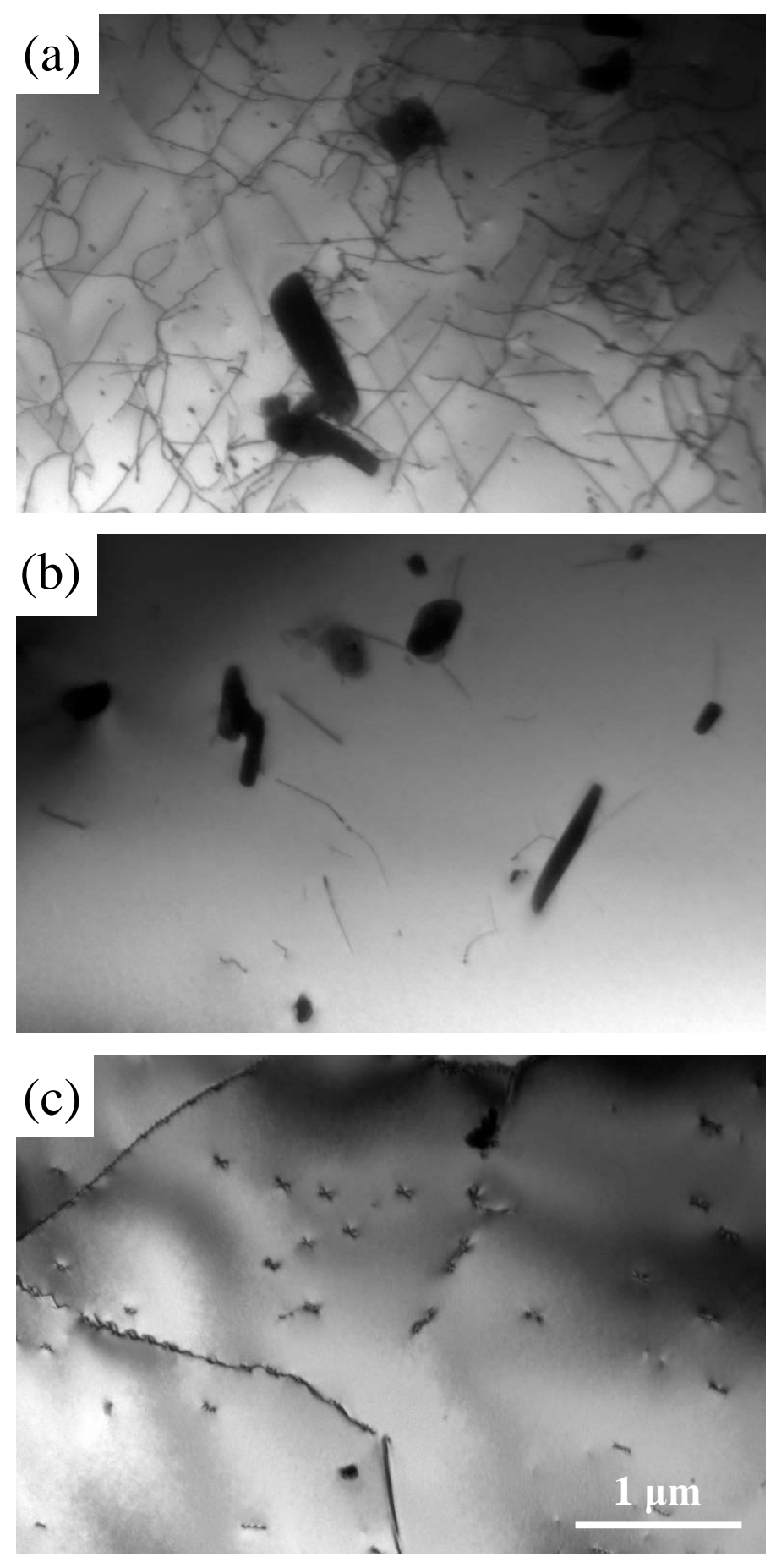

Fig. 5 TEM images of pre-aged gauge SUS444 samples: (a) PA-GA1 (0.3\%), (b) PA-GA2 (3.0\%) and (c) PA-GA3 $(14.3 \%)$. 

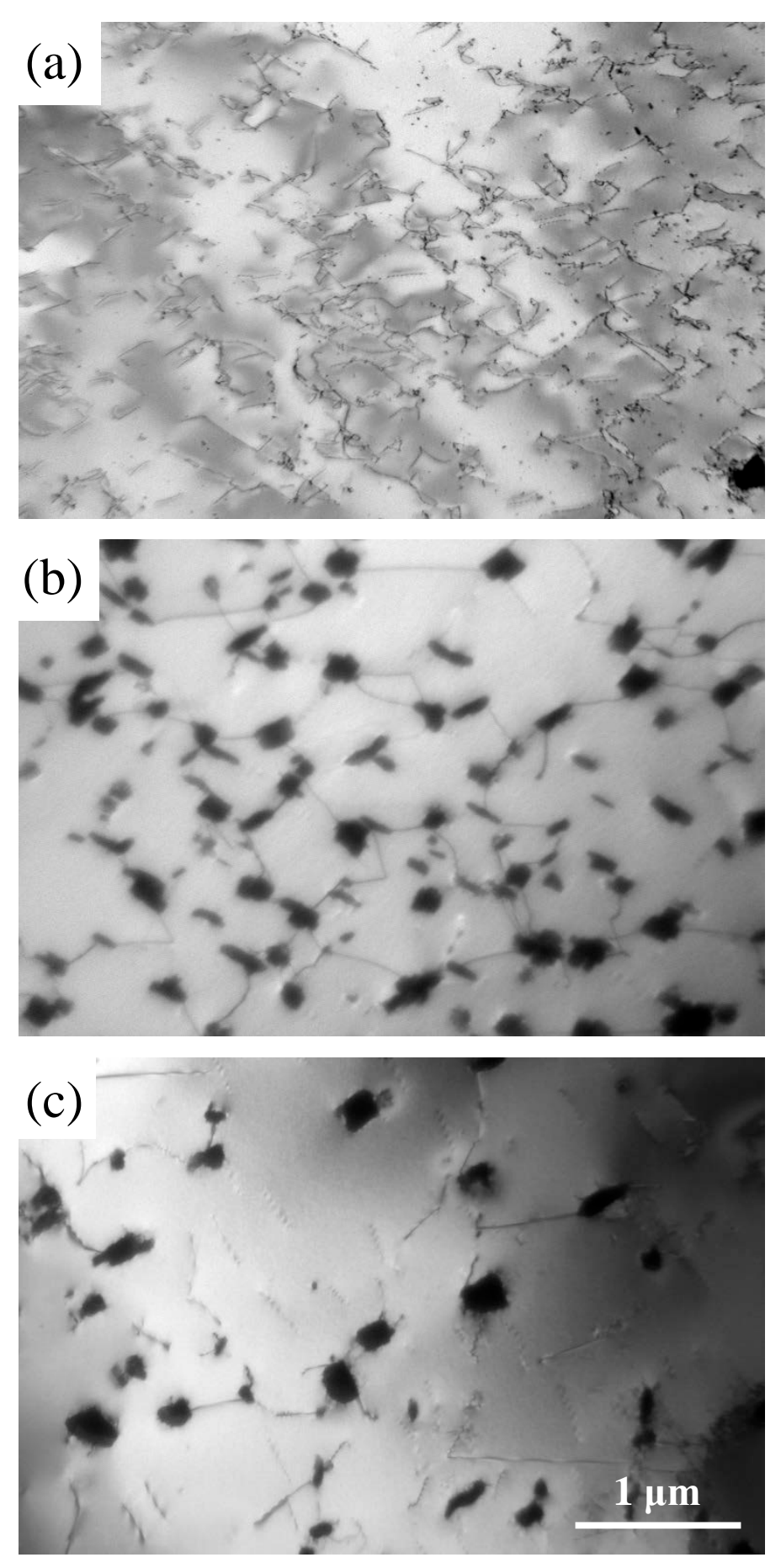

Fig. 6 TEM images of un-aged gauge SUS444 samples: (a) UA-GA1 (0.3\%), (b) UA-GA2 (0.9\%) and (c) UA-GA3 (3.0\%). 


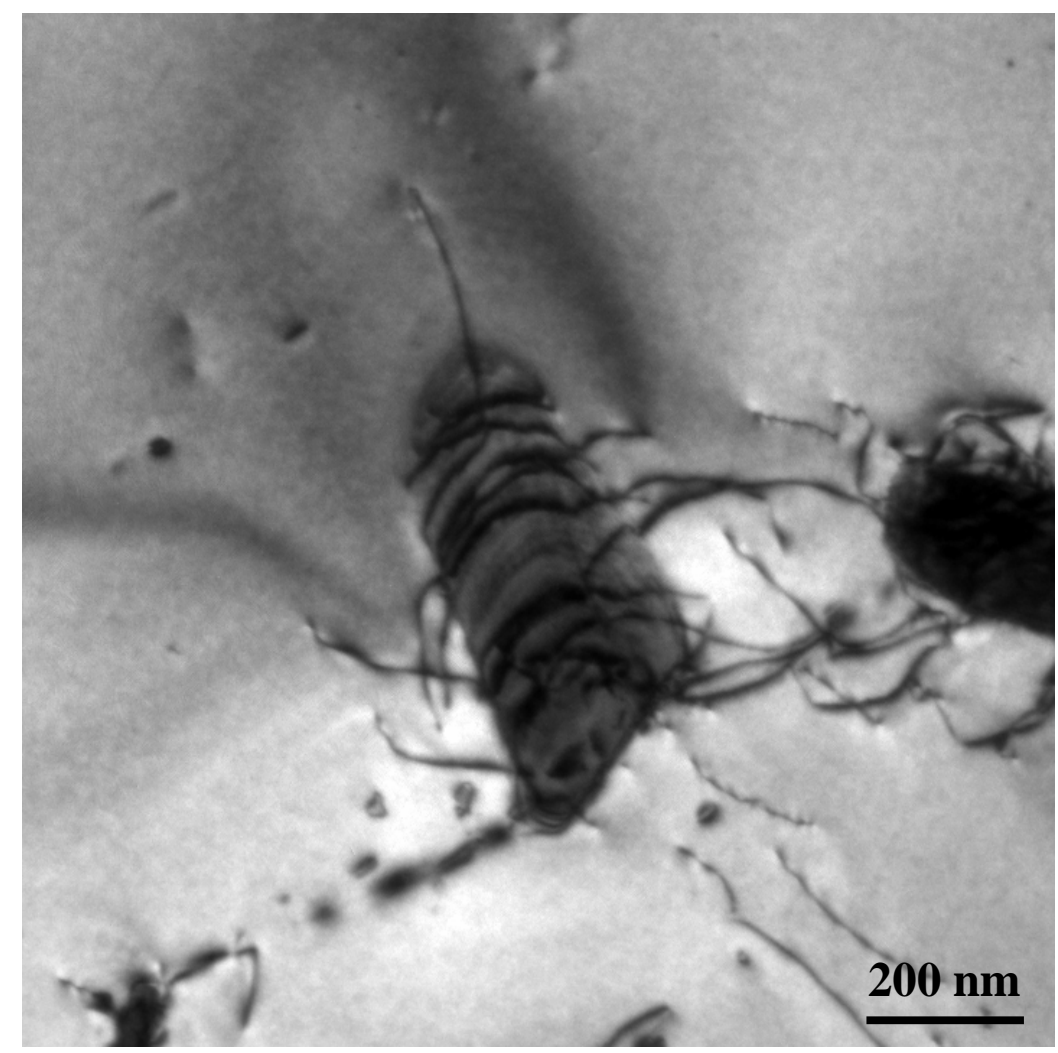

Fig. 7 TEM image of dislocation loops around Laves precipitate in PA-GA3. 


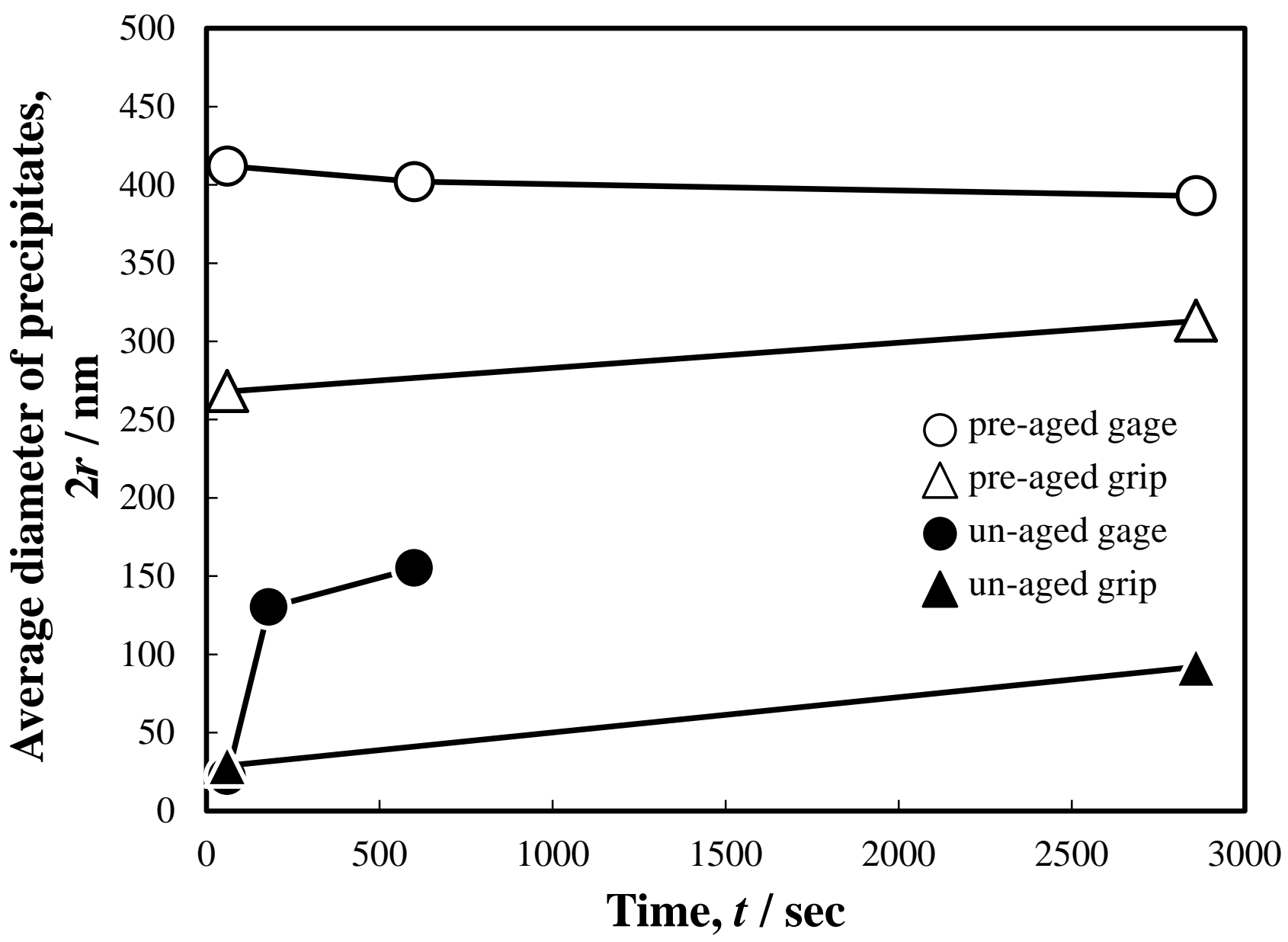

Fig. 8 Time and strain effects on average diameter of precipitates in pre-aged and un-aged samples. 


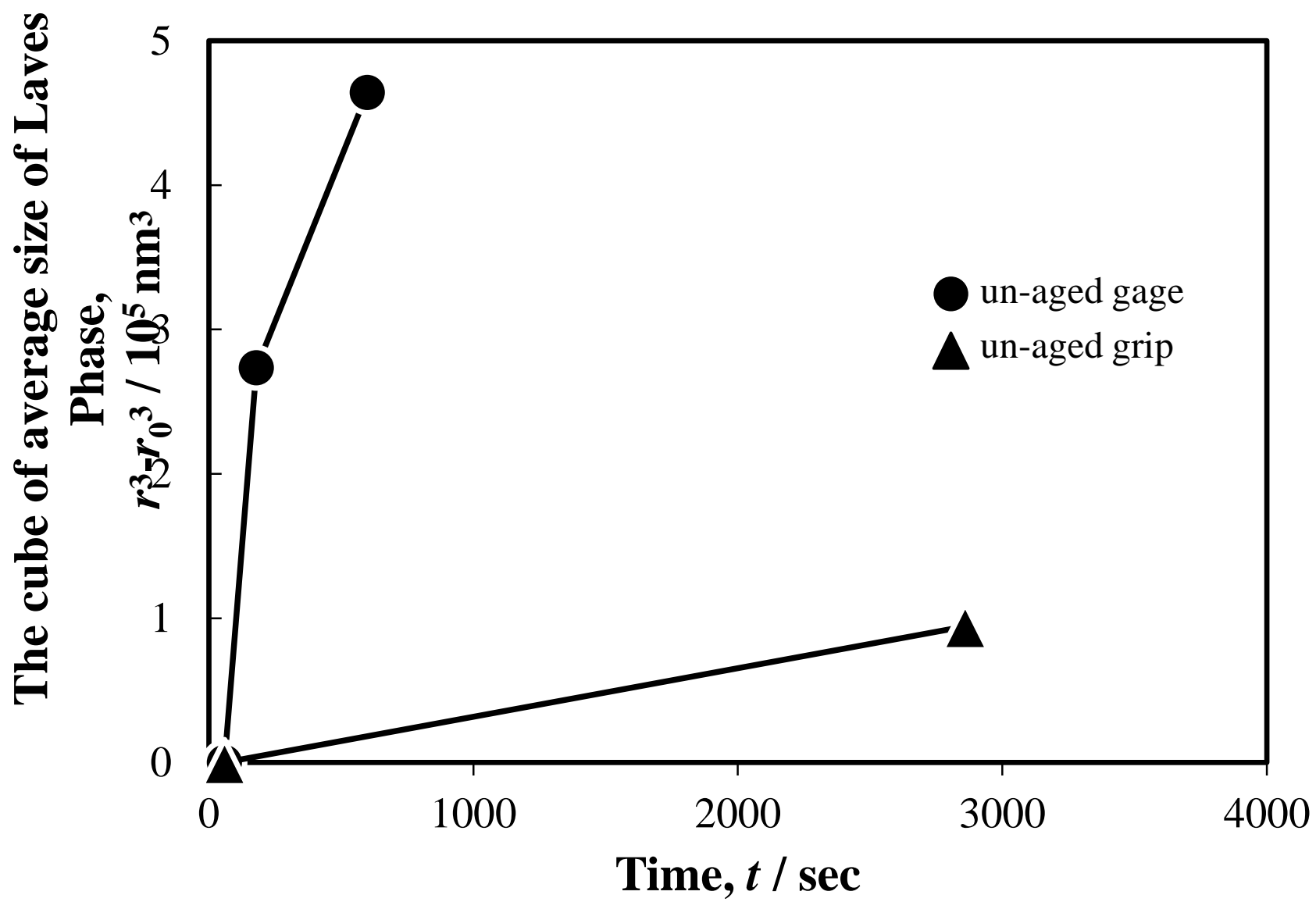

Fig. 9 Relationship between the cube of average size of precipitates and time in un-aged grip and gauge samples. 